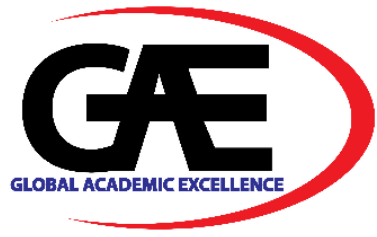

\title{
WORKING CONDITIONS OF THE FRONTLINE HEALTHCARE WORKERS IN THE COVID-19 PANDEMIC FROM A LEGAL VIEWPOINT
}

\author{
Harlida Abdul Wahab ${ }^{1 *}$, Nor Anita Abdullah², Asmar Abdul Rahim ${ }^{3}$
}

1 School of Law, College of Law, Government \& International Studies, Universiti Utara Malaysia, 06010 Sintok Kedah, MALAYSIA.

Email: harlida@uum.edu.my

2 School of Law, College of Law, Government \& International Studies, Universiti Utara Malaysia, 06010 Sintok Kedah, MALAYSIA.

Email: anita@uum.edu.my

3 School of Law, College of Law, Government \& International Studies, Universiti Utara Malaysia, 06010 Sintok Kedah, MALAYSIA.

Email: asmar@uum.edu.my

* Corresponding Author

\section{Article Info:}

\section{Article history:}

Received date: 09.11.2020

Revised date: 15.11 .2020

Accepted date: 10.12 .2020

Published date: 10.03.2021

\section{To cite this document:}

Wahab, H. A., Abdullah, N. A. \& Rahim, A. A. (2021). Working Conditions Of The Frontline Healthcare Workers In The Covid-19 Pandemic From A Legal Viewpoint. International Journal of Law, Government and Communication, 6 (22), 109-119.

DOI: $10.35631 /$ IJLGC.6220010.

\begin{abstract}
:
The outbreak of the COVID-19 pandemic has posed a major and unprecedented challenge to countries around the world. Other than threatening public health, economic and social livelihood, and wellbeing, it causes a significant impact on the healthcare industry and the workers. Healthcare is an essential service that is paramount where its interruption would endanger the life, health, and safety of all citizens, particularly during this pandemic. Also, the healthcare industry is one of the most hazardous environments to work in while healthcare workers are the most valuable resource who are exposed to occupational risks, in particular, hazards of infectious risks. This paper aims to look at the legal protections regarding the working conditions of the frontline healthcare workers during the pandemic of COVID-19. Using a doctrinal method, specific references are made to the Occupational Safety and Health Act 1994, and relevant policies/guidelines issued by the Ministry of Health and the Ministry of Human Resources. It is understood that the working conditions of the frontline healthcare workers are entirely protected by the legislation and guided through the policies and guidelines that are generally aligned with the international standards. Hence, the law and policy devices are found to be safeguarding the healthcare workers from physical and biological hazards, as well as psychological and physiological wellbeing that become part of the working conditions of the healthcare workers.
\end{abstract}




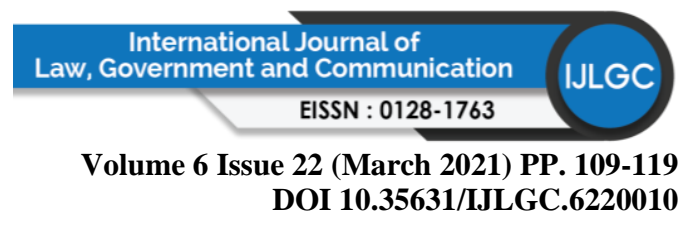

This work is licensed under $\underline{\mathrm{CC} B Y}$ 4.0

()(1)

Keywords:

COVID-19, Healthcare Workers, Safety And Health, Working Conditions, Law And Policy, Legal

\section{Introduction}

The global outbreak of the COVID-19 virus has affected millions of people. The virus poses a major and unprecedented challenge to economies and societies around the world. In addition to the threat and serious implications to the public health, economic and social disruption threatens the long-term livelihoods and wellbeing. Millions are affected by this global virus pandemic. It is, without doubt, having a significant impact on the healthcare services and the workers.

Presently, healthcare workers (HCWs) are every country's most valuable resource. A healthcare worker is one who delivers care and services to the sick and ailing either directly as doctors and nurses or indirectly as aides, helpers, laboratory technicians, or even medical waste handlers (Joseph \& Joseph, 2016). At the same time, the healthcare industry is seen as the most hazardous environment to work in. An adequate health workforce is central to universal health coverage and positive public health outcomes (Nkomazana, Mash, Shaibu \& Phaladze, 2015). Regulation 2 of The Prevention and Control of Infectious Diseases (Measures Within the Infected Local Areas) Regulations 2020, Malaysia lists down all the essential services that shall be provided during the period of the movement order, which includes health care and medical.

Being categorised as one of the essential services, healthcare and medical services are necessary without which, their interruption would endanger life, health and safety of the whole citizens. When the outbreak of COVID-19 was declared by the WHO as a worldwide pandemic, all nations that are potentially affected come with strategic action plans to counteract its widespread. Thus, restricting public movement through a Movement Control Order (MCO) is a drastic measure taken to stop or control the spread of the virus. The aim is to prevent and avoid more people from being infected by this life-threatening COVID-19 pandemic (Prime Minister Official Website, 2020). The healthcare workers have to be facilitated with a good response from the public in ensuring the infected numbers of people to be reduced.

From the legal perspective, other than the $\mathrm{MCO}$, the working conditions of the frontliners in the healthcare industry are paramount. The HCWs are facing infectious risks and constantly exposed to a complex variety of health and safety hazards in the course of their work. The International Labour Organization (ILO) reported that millions of HCW suffer from workrelated diseases and accidents, and many succumb to occupational hazards (International Labour Organization, 2018). The reasons for this are varied ranging from heavy exposure to the pathogen at the workplace to poor infection control measures implemented at the hospitals and laboratories (Joseph \& Joseph, 2016). The occupational health services in health care facilities have an important role for protecting health workers as well as ensuring the business continuity of health care services (World Health Organization, 2020). Indeed, it needs special attention to cope with, particularly in handling and managing the spread of COVID-19 virus. Accordingly, the protection of HCWs is one of the priorities in response to this outbreak, especially those who directly deal with and in-charge of the patients of COVID-19. 


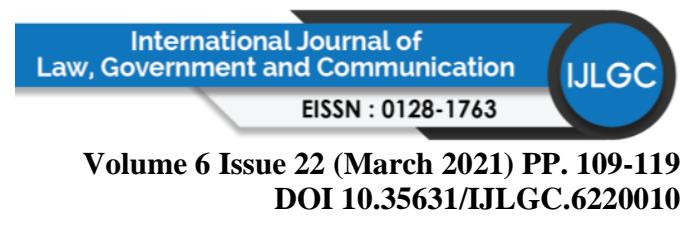

The working conditions of the HCWs are critical so that they can be safe and protected from the occupational hazards and infectious risks of the COVID-19 virus. It is the aim of this paper to look at the aspect of working conditions as one of the elements of social protection of the healthcare workers. The authors discuss the current law and policy that are applicable and related to the frontline HCWs particularly during the pandemic of COVID-19. To be specific, references are made to the Occupational Safety and Health Act 1994, and relevant policy/guidelines by the Ministry of Health $(\mathrm{MOH})$ and the Ministry of Human Resources (MOHR).

\section{Methodology}

Using a doctrinal method, the main references are the Occupational Safety and Health Act 1994, and the relevant policies/guidelines issued by the MOH and MOHR regarding the working conditions of the HCWs, specially the frontliners who are handling suspected/confirmed COVID-19 patients.

\section{Literature Review}

Social protection approach that is part of human rights (Samad \& Shahid, 2018), is instrumental to the achievement of a broad range of development goals including poverty reduction, education, health, social inclusion and empowerment among others. The emergence of the evolution in social protection is becoming a prominent issue in many parts of the world as it contributes to social and economic sustainability and development amongst the public. The scope of social protection has five major aspects, namely labour markets, social insurance, social assistance or welfare services, micro and area-based approaches and child protection (Asian Development Bank, 2001). For the purpose of this paper, the authors are looking at the first element that is the labour market policy that involves improving working conditions as a means to support and give protection to the healthcare workers. Furthermore, protecting workers in the workplace by strengthening OSH measures is one of the four pillars of actions defined by the ILO to lessen the impact of COVID-19 (International Labour Organization, 2020).

Regarding the aspect of working conditions, generally, employers have moral and legal obligations to keep workers safe and healthy. In the case of HCWs, they play the vital role as the most valuable resource for health (World Health Organization, 2018). The HCWs are at the front line of any outbreak responses and as such are exposed to hazards that put them at risk of infection. They are facing pathogen exposure, long working hours, psychological distress, fatigue, occupational burnout, stigma, as well as physical and psychological violence. As other categories of workers in the mining or construction industry, HCWs are in need of protection from workplace hazards particularly when fear of contracting infectious diseases is primarily responsible for high attrition rates among them (Joseph \& Joseph, 2016). Lin et al. (2020) concluded that hospitals and healthcare facilities have many unique occupational health and safety hazards that can potentially affect the health and performance of healthcare professionals therefore, controlling, eliminating, or reducing exposure can contribute to a stronger healthcare workforce with great potential to improve patient care and the healthcare system.

In the case of COVID-19, the situation of the HCWs is worsening considering severe and high risk of the virus may cause. Figures from China's National Health Commission showed that more than 3300 HCWs have been infected as of early March 2020, while in Italy, 20\% of responding HCWs were infected and some have died (The Lancet, 2020). In Malaysia, over Copyright $\odot$ C GLOBAL ACADEMIC EXCELLENCE (M) SDN BHD - All rights reserved 


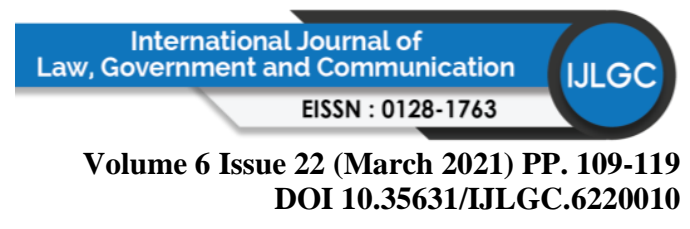

600 HCWs are infected with COVID-19 (New Strait Times, September 18, 2020). This figure is very significant to show that HCWs are exposed to hazards that put them at risk of infection at any time.

COVID-19 has exposed healthcare workers and their families to unprecedented levels of risk. Data from many countries indicated that COVID-19 infections among health workers are far greater than those in the general population where around $14 \%$ of cases reported to WHO are among health workers, while in some countries, the proportion can be as high as $35 \%$ with thousands of those infected have lost their lives worldwide (World Health Organisation, September 17, 2020). Lai, Ma, Wang et al. (2020), in a mental health study of more than 1200 healthcare workers from 34 hospitals in China providing COVID-19 care, revealed the factors contributing to psychological distress such as emotional strain and physical exhaustion, caring for co-workers who may become critically ill and sometimes die from COVID-19, shortage of PPE and concerns about infecting family members with the virus. To lower the risk of infection and spreading the virus to others including families, healthcare workers decided to socially isolate themselves where some have chosen to have their children and family members to spend time with relatives away from them and others have isolated themselves even within their own homes, which all these are causing mental health issues to some of them (Gold, 2020). HCWs in Malaysia were also reported as feeling stressed, tired, burnt out, and sad because some of them have not seen their families for months, while some reported sensing discrimination from the public when they are perceived as "infected persons" since they are working in hospitals. A number of studies found the psychological effects of HCWs due to COVID-19 pandemic such as uncomfortable and stressful conditions, social pressures, mental health issues and fatigueness (Waleed et al., 2020; Jianbo et al., 2020; Bakar \& Ramli, 2020; Tandon, 2020).

The working conditions must be safe and healthy to motivate a pleasant working environment. Safety itself should include physical, emotional and mental wellbeing in and out of the workplace. In the case of HCWs, they must be healthy, alert and engaged while at work, so in turn, this may avoid negligence and oversight that can lead to accidents and injury. In the case of COVID-19, psychosocial hazards such as shift work, anxiety, stress, depression and burnout must be taken care of earnestly. For this reason, the World Health Organization (WHO) and many other international health agencies and bodies produced guidelines and manuals with sufficient psychosocial support systems particularly for the healthcare frontliners in order to minimize the effects that may disrupt their psychological well-being (Bakar \& Ramli, 2020). The WHO has launched the Health Worker Safety Charter as a step towards ensuring that health workers have the safe working conditions, the training, the pay and the respect they deserve (World Health Organisation, September 17, 2020). Therefore, it is increasingly important to address the health care needs of the healthcare workers in responding to the demands of caring for patients with COVID-19 (Ayanian, 2020). Indeed, protecting health workers is key to ensuring a functioning health system and a functioning society.

\section{The Law and Policy Relating to Working Conditions of Healthcare Workers}

Lin et al. (2020) identified the occupational health and safety hazards, injuries, and diseases affecting healthcare professionals working in hospitals and healthcare facilities and these include biological hazards, chemical hazards, physical hazards, ergonomics hazards and psychosocial hazards. As far as occupational safety and health is concerned, the significant law that governs this matter is the Occupational Safety and Health Act 1994 (OSHA). Therefore, as mentioned earlier, the working conditions of the healthcare workers for the purpose of this Copyright (C) GLOBAL ACADEMIC EXCELLENCE (M) SDN BHD - All rights reserved 


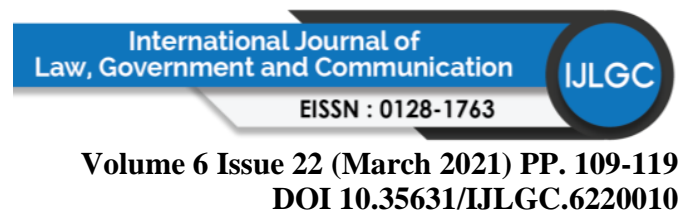

paper are viewed by considering the OSHA and its regulations, together with the policy guidelines issued by the Ministries. This part therefore will be divided into two: the law and the policy guidelines.

\section{The Law - Occupational Safety and Health Act 1994}

In the context of the legislation, Occupational Safety and Health Act 1994 (OSHA) is the main statute governing occupational safety and health in almost all industries in Malaysia including the healthcare and medical industry. The Act has its objectives, one of them is to secure safety, health and welfare of persons at work (Section 4). The word safety here is defined as the absence of risk to injury; health as a state of complete physical, mental and social well-being and not merely the absence of disease; and welfare should include provision of first aid, drinking water, canteen and toilets for men and women (Department of Occupational Safety and Health Malaysia, 2006). The Act stipulates the important obligations of the employers and employees at the workplace. Section 15 of the Act clearly requires the employer to ensure, so far as is practicable, that the safety, health and welfare of all employees at the workplace are taken care of. This duty includes providing and maintaining a safe work environment without risk to health and providing adequate facilities for the welfare of the working people, including the visitors. To relate this statutory duty with the situation of COVID-19, this provision imposes the employer to ensure, so far as is practicable, the following:

(a) Compliance with the legal requirements and related safe work procedures for COVID-19. For example, restricting a certain number of employees in an isolation room.

(b) The workplace is safe and without risk of infection to the workers and visitors. For example, to carry out body temperature measurements and symptomatic screening to all workers including visitors, before being authorized into the workplace.

(c) The exit and entry from work is safe and without risk of COVID-19 infection. This can be done by having two different lanes for coming in and going out so as to promote social and physical distancing thus avoiding any physical contact.

(d) All facilities and welfare of employees are adequately provided for COVID-19 risk control.

(e) Information, training and supervision related to COVID-19 is prepared and disseminated. For example, to provide informational materials and proper procedure for application of PPE, and training for handling of COVID-19 patients.

(f) Develop policies and procedures for employees to report when they are sick or experiencing symptoms of COVID-19.

(g) Provide appropriate PPE to employees according to the needs of their respective work and to comply with the related SOPs (for example, to adhere to the Movement Control Order, Restoration Movement Control Order, Enhanced Movement Control Order, and others, as issued by the National Safety Council (MKN) from time to time.)

The word "so far as is practicable" potentially gives some defence to the employer when the duty is seen as not mandatory. Here, the question of practicability must take into account the severity of the risk in question, knowledge about the risk and ways to remove or reduce it, the availability and suitability of ways as well as costs to remove it. Common practice and knowledge throughout the industry should be taken into account when considering 'practicable'. If it is too costly and does not commensurate with the expenses of the employer, Copyright (C) GLOBAL ACADEMIC EXCELLENCE (M) SDN BHD - All rights reserved 


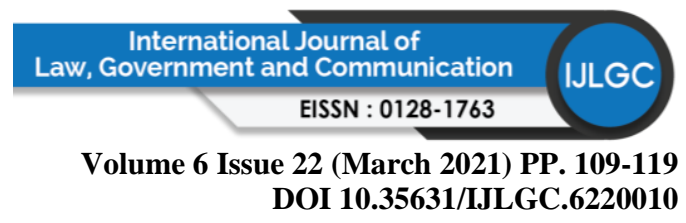

it may not be practicable although the matter is within the knowledge of the employer. In a case involving a cleaning services company, UEM Edgenta that was claimed by the unionised workers that they were denied personal protective equipment (PPE) such as surgical face masks and gloves despite having to sanitise COVID-19 wards in public hospitals. Nevertheless, the company denied saying that it was part of a global shortage since the start of the pandemic and in fact, the company had taken extra efforts to procure PPE to ensure the safety of staff despite significantly higher cost (Bunyan, 2020).

In promoting the health and safety environment, the Act also promotes an occupational environment which is adapted to the physiological and psychological needs. It is important for the employer to provide a hospitable and conducive environment for the health, safety and welfare of HCWs so as to support their physiological and psychological needs. For example, working in a hot environment and wearing PPE in a long hour would require appropriate restwork regime as this is considered as a psychosocial hazard in the workplace. Providing adequate and suitable PPE to the staff as ensuring a safe workplace for the workers is a legal requirement that is mandatory under the law. It is to note that the working environment shall include the workplace itself, physical as well as psychological environment.

It is important to know that the duty to ensure health and safety at the workplace does not lie on the employer alone. It is also the responsibility of the employee to take reasonable care and cooperate with the employer especially in ensuring safety and avoiding risk and hazards at work. Hence, HCWs have to cooperate such as to wear PPE provided and comply with the employers' instructions or measures in OSH matters. Responsibilities of the workers are stipulated under section 24 of OSHA. In brief, the HCWs must do the following:

(a) Responsible for safety and health of him/herself, co-workers and other people who may be affected while running the work.

(b) Adhere to safe work procedures and wear PPE prescribed while working.

(c) Application of face shield, face mask or other protective equipment when carrying out work especially when involving the public.

(d) Employees with COVID-19 symptoms shall immediately notify his/her employer, supervisor or coordinator for further action.

(e) Comply with any rules and instructions prescribed by the employer related to COVID19 and any guidelines set by the MOH, WHO, ILO and related agencies.

It is to note that safety and health are crucial parts especially in dealing with COVID-19 issues. Any accident or occupational disease arising out of the negligence of either employer or employee may result in dispute and claim for damages. In the case of Abdul Rahim b. Mohamad $v$ Kejuruteraan Besi Dan Pembinaan Zaman Kini [1998] 4 MLJ 323, the court had referred to section 24(1) of the OSHA which provides:

(1) It shall be the duty of every employee while at work-

(a) to take reasonable care for the safety and health of himself and of other persons who may be affected by his acts or omissions at work; 


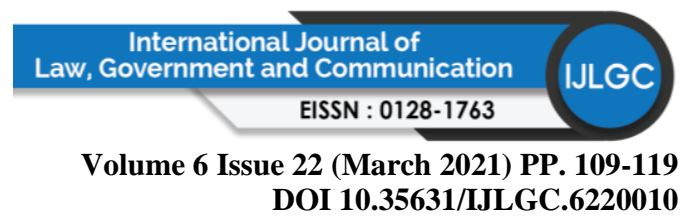

(d) to comply with any instruction or measure on occupational safety and health instituted by his employer or any other person by or this Act or any regulation made thereunder.

Generally, the Act also imposes penalty on a person who contravenes the provisions of section 15 , with a fine not exceeding fifty thousand ringgit or to imprisonment for a term not exceeding two years or to both. In the case of contravention of section 24, such person shall be guilty of an offence and on conviction, shall be liable to a fine not exceeding one thousand ringgit or to imprisonment for a term not exceeding three months or to both.

Additionally, there are also few other related regulations that are relevant in the case of HCWs and COVID-19, namely, Use and Standard of Exposure of Chemicals Hazardous to Health Regulations 2000 and Notification of Accident, Dangerous Occurrence, Occupational Poisoning, and Occupational Disease (NADOPOD) Regulations 2004. As for NADOPOD, it is the duty of the employer or any person who encountered a dangerous occurrence or occupational disease to notify the employer for appropriate action. This is in line with section 32 of OSHA about the notification of accidents, dangerous occurrence occupational poisoning and occupational diseases. It says that an employer shall notify the nearest occupational safety and health office of any accident, dangerous occurrence, occupational poisoning or occupational disease which has occurred or is likely to occur at the place of work. The medical doctor who attended the patient who believed to be suffering from the disease, which in this case, probably COVID-19, also may report to the Director-General of DOSH.

\section{The Policy/Guidelines}

The Department of Safety and Health (DOSH) under the MOHR of Malaysia has come out with a Safety Work Procedure Prevention of COVID-19 at the Workplace (Safety Procedure). This Safety Procedure briefly but clearly explains about the duties of employers, employees, coordinator, supervisor and emergency response team at the workplace. It also includes general rules to be adhered to before entering the workplace, while working and when holding meetings. In other words, DOSH as a relevant department that is enforcing safety and health at the workplace also has introduced a specific procedure for both employers and employees including the HCWs.

Other than the Safety Procedure, the $\mathrm{MOH}$ also comes with different guidelines and standard operating procedures (SOPs) from time to time. The Guidelines COVID-19 Management In Malaysia No. 5/2020 has issued different annexes comprising SOPs, flow charts, variety guidelines and many more for the purpose of managing and handling COVID-19 cases. Among them are Annex 21: Management of Healthcare Workers During COVID-19 Pandemic (known as Annex 21) and Annex 2d: Work Process in Management of Suspected COVID-19 Patients in Emergency and Trauma Department (known as Annex 2d). For the HCWs, these instructional materials, work process and guidelines in managing COVID-19 ensure their working conditions that align with the legislative requirement on safety and health.

The primary objective of Annex $2 \mathrm{~d}$ is to facilitate the HCWs in the Emergency and Trauma Department (ETD) in carrying out the management of suspected COVID-19 patients, hence, optimising the screening, detection, isolation and institution of therapeutic intervention (Ministry of Health, 2020). This is imperative as early risk detection is paramount in ensuring effective prevention and control of the disease. Additionally, Annex 2d:

Copyright $\odot$ GLOBAL ACADEMIC EXCELLENCE (M) SDN BHD - All rights reserved 


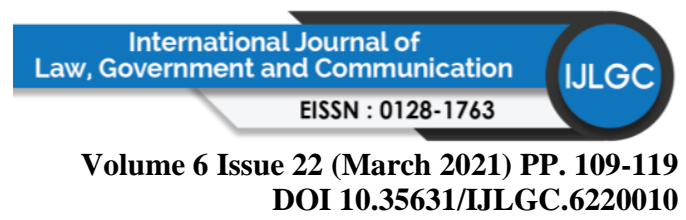

(a) serves to protect the HCW from being exposed to COVID-19;

(b) advocates the separation of walk-in patients with respiratory symptoms and without respiratory symptoms as early as primary triage contact. This will minimise the risk of disease transmission to the HCW and other patients.

(c) address the functions of Pre-hospital Care and Ambulance Services (PHCAS) in various aspects of COVID-19 operations.

When transporting the patients that suspected or confirmed COVID-19, the HCWs are required to have specific type of PPE, such as N95 mask, isolation gown (fluid repellent long-sleeved gown), gloves, eye protection (face shield/goggles) and head cover. Even the seating arrangement in the ambulance should be adhered. There is also a specific guideline for HCWs in the Emergency and Trauma Department (ETD). Therefore, different treatments and zones require different types of PPE when HCWs are advocated to wear appropriate PPE based on the treatment zones and type of procedures. For example, HCWs attending acute respiratory infection patients should wear surgical masks, long-sleeved plastic aprons, gloves and face shields/goggles.

With regards to Annex 21, generally the management of HCWs does not vary much. Nevertheless, due to the unprecedented and severe case of the COVID-19 pandemic, the working conditions must be carried out within the new norms environment. For this reason, Annex 21 lists down the new norms in general such as practice of social and physical distancing, whether at the counter, common area, prayer room, and so on; hand hygiene; use of PPE; screening and daily temperature and follow-up of the HCWs on home surveillance. In addition, daily communication and risk communication with the supervisor are carried out for the HCWs to update the information, remind the safety and health measures before commencing work including any consultation. The OSH Unit or Safety and Health Committee of the healthcare facility is responsible for the monitoring of the HCWs. The HCWs with high risk conditions should not be allowed to provide care to patients suspected or confirmed COVID-19. If the HCWs are confirmed COVID-19, they are subject to be reported to three reporting systems which means that the procedures are stringent so that exposure risks can be strictly assessed. The exposed HCWs will be properly managed and categorised to high-risk exposure, medium-risk exposure or low-risk exposure.

In addition to the physical elements and approach to safety and health, it is good to discover that the MOH also provides psychological support and counselling assistance for HCWs. Mental health assessment and psychological first aid shall be conducted by the Mental Health and Psychosocial Support Team. All HCWs are also supported with mental health preparedness prior to pre-deployment. Upon post-deployment, HCWs will receive a Mental Health Alert Card in line with Annex 33: Mental Health and Psychosocial Support in COVID-19 (Ministry of Health, 2020).

\section{Discussion}

The COVID-19 pandemic has changed the way people work all over the world. Owing to its unprecedented case, safe and healthy workplace conditions are fundamental to the people at Copyright $\odot$ GLOBAL ACADEMIC EXCELLENCE (M) SDN BHD - All rights reserved 


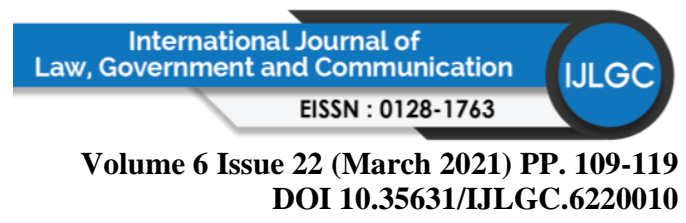

work and this is even more intense for the HCWs who are exposed to the infectious risk. It is evidence from the above discussion that the OSHA is the major legislation that governs safety, health and welfare of the workers and this should also cover the HCWs and the healthcare industry. Furthermore, the concept of OSHA is self-regulatory where the responsibility for managing safety and health lies with those who create the risks and those who work with the risks. In regard to the case of COVID-19 and HCWs, it is the MOH together with the MOHR who come up with the special guidelines and procedures for those who are working with the risks. Although working in new norms, safety and health matters are still rooted from the OSHA 1994.

Therefore, as far as the working conditions of the HCWs is concerned, the aspects of safety and health should comprise the holistic approach encompassing physiological and psychological including psychosocial hazards such as stress, anxiety, excessive workloads and burnout. From the guidelines discussed above, Malaysia has taken steps in ensuring protection of the HCWs. The implementation of the special guidelines and procedures for managing any risk, hazard, possibility and matter relating to COVID-19 show that the Government and the Ministries (MOH and MOHR) are very serious in safeguarding the working conditions and other safety and health aspects of the HCWs. In fact, other than the above guidelines, there are many other lists of guidelines and procedures imposed on other sets of population in containing the spread of coronavirus. All the actions taken clearly showed the Government has tried the best to ensure the handling and managing the pandemics are in order. In terms of psychosocial support, the $\mathrm{MOH}$ has established a Crisis Preparedness and Response Centre (CPRC) that functions to provide support services not limited to frontline HCWs but including the public. The services are being managed by psychiatrists, clinical psychologists, and counsellors to help HCWs and the public to handle depression, anxiety, insomnia, distress, and stigmatization that they faced during the COVID-19 pandemic.

It is worth mentioning, other than the elements of skills, knowledge and experience in handling the job, the case of COVID-19 may require extra self-care and management for the HCWs. The legislative approach therefore can be an effective means in managing the pandemic, particularly in regard to the working conditions of the HCWs. In line with the provision of Section 24 of OSHA 1994 as mentioned, HCWs therefore should be responsible to themselves. Additionally, specific guidelines that deal with a variety of COVID-19 cases should become supplementary for the avoidance and preparedness of the infectious risks and hazards to the HCWs. Since safety itself should encompass physical, emotional and mental wellbeing; physiological and psychological aspects, the legislative framework, guidelines and procedures together with other support services of the Ministries found to be accommodating the frontline HCWs.

\section{Conclusion}

The COVID-19 pandemic has been challenging, and it has put significant pressure on the healthcare system. The HCWs are facing significant increases of infectious risks and hazards at work due to the threat exposure. This fact has impinged on their working conditions. As an essential service, the matters of safety, health and welfare of HCWs are essential because the frontliners endanger their lives, devote their time and energy, show their commitment and unwavering efforts to battle this pandemic for the benefit of the nation. In facing these challenges, working conditions as one of the elements of social protection is critical for HCWs. It is therefore highly recommended for the healthcare employers to strictly adhere to the Copyright (C) GLOBAL ACADEMIC EXCELLENCE (M) SDN BHD - All rights reserved 


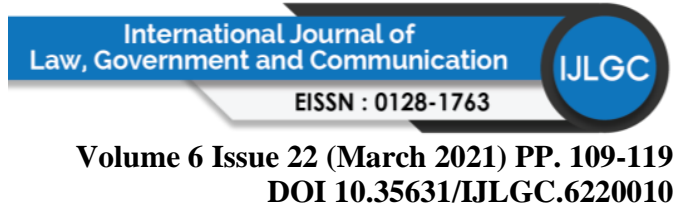

relevant legal requirements and policy guidelines that cover multiple aspects of HCWs involvement, from practicing new norms in the healthcare setting to specific actions involving the pandemic. For the HCWs, it is crucial for them to participate and endure in all protocols and guidelines to maintain the best standards of infectious disease under control.

\section{Acknowledgement}

This paper is part of a project funded by the Ministry of Higher Education under the COVID19 Special Research Grant, and supported by the Research and Innovation Management Centre, Universiti Utara Malaysia (Research ID 10008864 \& SO Code 14696). Thank you.

\section{Reference}

Ayanian, J. Z. (2020). Editor's Comment - COVID-19: Mental Health Needs of Health Care Workers Providing Frontline COVID-19 Care. Retrieved from https://jamanetwork.com/channels/health-forum/fullarticle/2764228

Bakar, A.Y.A \& Ramli, S. (2020). Psychosocial support for healthcare frontliners during COVID-19 pandemic in Malaysia. Asian J Psychiatr, 54, 102272. Doi: 10.1016/j.ajp.2020.102272

Bunyan, J. (2020). After picketers arrested outside Ipoh hospital, UEM Edgenta claims alleged union-busting was part of 'insourcing' deal. Malay Mail. Retrieved on October 10, 2020 from https://www.malaymail.com/news/malaysia/2020/06/04/after-picketers-arrestedoutside-ipoh-hospital-uem-edgenta-claims-alleged-u/1872334

Department of Occupational Safety and Health. (2006). Guidelines on Occupational Safety and Health Act 1994 (ACT 514). Malaysia: Percetakan Nasional Malaysia Berhad.

Gold, J. (2020). The Covid-19 crisis too few are talking about: health care workers' mental health. April 3, 2020. Retrieved on June 18, 2020 from https://www.statnews.com/2020/04/03/the-covid-19-crisis-too-few-are-talking-abouthealth-care-workers-mental-health/

International Labour Organization. (2020). ILO to release latest analysis of impact of COVID19 on global employment, informal economy and enterprises. Retrieved on April 27, 2020 from https://www.ilo.org/global/about-theilo/newsroom/news/WCMS_742971/lang--en/index.htm

International Labour Organization (ILO). (2018). International labour standards on occupational safety and health. Retrieved on June 17, 2020 from http://www.ilo.org/global/standards/subjects-covered-by-international-labourstandards/occupational-safety-and-health/lang-en/index.htm

International Labour Organization. (2020). COVID-19 and the world of work - Country policy responses. Retrieved on October 10, 2020 from https://www.ilo.org/global/topics/coronavirus/regional-country/countryresponses/lang--en/index.htm

Jianbo, L., Simeng, M., Ying, W., Zhongxiang, C., Jianbo, H., Ning, W., Jiang, W., Hui, D., Tingting, C., Ruiting, L., Huawei, T., Lijun, K., Lihua, Y., Manli, H., Huafen, W., Gaohua, W., Zhongchun, L. \& Shaohua, H. (2020). Factors associated with mental health outcomes among health care workers exposed to Coronavirus Disease 2019. JAMA Network Open. 3(3), 1-12. doi:10.1001/jamanetworkopen.2020.3976

Joseph, B. \& Joseph, M. (2016). The health of the healthcare workers. Indian J Occup Environ Med. May-Aug; 20(2): 71-72. doi: 10.4103/0019-5278.197518

Lin, C. H., Lin, Y. W., Yang C. M., Hung, L. C., Wang, J. Y. \& Lin, M. H. (2020). Occupational health and safety hazards faced by healthcare professionals in Taiwan: A systematic 
review of risk factors and control strategies. SAGE Open Medicine. 8. doi.org/10.1177/2050312120918999

Ministry of Health. (2020). Annex 2d. Retrieved on October 5, 2020 from http://covid19.moh.gov.my/garis-panduan/garis-panduan-

kkm/Annex_2d_GUIDELINES_ON_THE_MX_OF_SUSPECTED_COVID19_PATI ENT_IN_THE_ETD_2.10.20.pdf

Nkomazana O, Mash, R., Shaibu, S. and Phaladze, N. (2015). Stakeholders' Perceptions on Shortage of Healthcare Workers in Primary Healthcare in Botswana: Focus Group Discussions. PLoS One. 10(8): e0135846. doi: 10.1371/journal.pone.0135846.

Prime Minister Office Official Website. (2020). Movement control order. Retrieved on May 11, 2020 from at https://www.pmo.gov.my/2020/03/movement-control-order/

Samad, S. A. \& Shahid, K. M. (2018). Social Protection Programme in Malaysia. Do We Need Integration? International Journal of Children, Women, Elderly and Disable People. 4, 71-79.

Tandon, R. (2020). The COVID-19 pandemic, personal reflections on editorial responsibility. Asian J. Psychiatr. 50, 102100.

The Lancet. (2020). Editorial COVID-19: Protecting health-care workers. 395 (10228), 922. doi.org/10.1016/S0140-6736(20)30644-9

Waleed, R., Sonia, M. \& Shamim, M. (2020). Mental health of medical workers in Pakistan during the pandemic COVID-19 outbreak. Asian J. Psychiatr. 51, In-Press.

World Health Organization \& International Labour Organization. (2018). Occupational safety and health in public health emergencies: A manual for protecting health workers and responders. Geneva.

World Health Organization. (2020, March 9). COVID 19: Occupational Health. Retrieved on September 23, 2020 from https://www.who.int/news-room/detail/09-03-2020-covid19-occupational-health.

World Health Organization. (2020, September 17). Keep health workers safe to keep patients safe: WHO. Retrieved on October 10, 2020 from https://www.who.int/newsroom/detail/17-09-2020-keep-health-workers-safe-to-keep-patients-safe-who. 